\title{
Green Tea Extract Concurrent with an Oral Nutritional Supplement Acutely Enhances Muscle Microvascular Blood Flow without Altering Leg Glucose Uptake in Healthy Older Adults
}

\author{
Ushnah S. U. Din ${ }^{1,+}$, Tanvir S. Sian ${ }^{1,2,+}$, Colleen S. Deane ${ }^{3,4,+} \mathbb{D}$, Ken Smith ${ }^{1} \mathbb{D}$, Amanda Gates ${ }^{1}$, \\ Jonathan N. Lund ${ }^{1,2}{ }^{\mathbb{D}}$, John P. Williams ${ }^{1,2}$, Ricardo Rueda ${ }^{(\mathbb{D})}$, Suzette L. Pereira ${ }^{6} \mathbb{D}$, Philip J. Atherton ${ }^{1, *, \ddagger(\mathbb{D})}$ \\ and Bethan E. Phillips $1, *, \ddagger$
}

check for updates

Citation: Din, U.S.U.; Sian, T.S.; Deane, C.S.; Smith, K.; Gates, A.; Lund, J.N.; Williams, J.P.; Rueda, R.; Pereira, S.L.; Atherton, P.J.; et al. Green Tea Extract Concurrent with an Oral Nutritional Supplement Acutely Enhances Muscle Microvascular Blood Flow without Altering Leg Glucose Uptake in Healthy Older Adults. Nutrients 2021, 13, 3895. https://doi.org/10.3390/nu13113895

Academic Editor: Carmen PatinoAlonso and Manuel A. Gomez-Marcos

Received: 29 September 2021

Accepted: 28 October 2021

Published: 29 October 2021

Publisher's Note: MDPI stays neutral with regard to jurisdictional claims in published maps and institutional affiliations.

Copyright: (c) 2021 by the authors Licensee MDPI, Basel, Switzerland This article is an open access article distributed under the terms and conditions of the Creative Commons Attribution (CC BY) license (https:// creativecommons.org/licenses/by/ $4.0 /)$
1 MRC-Versus Arthritis Centre for Musculoskeletal Ageing Research and National Institute for Health Research Nottingham Biomedical Research Centre, School of Medicine, University of Nottingham,

Derby DE22 3DT, UK; ushnah.din@nottingham.ac.uk (U.S.U.D.); tanvirsian@gmail.com (T.S.S.);

ken.smith@nottingham.ac.uk (K.S.); amanda.gates@nottingham.ac.uk (A.G.); jon.lund@nottingham.ac.uk (J.N.L.); john.williams7@nottingham.ac.uk (J.P.W.)

2 Department of Surgery and Anaesthetics, Royal Derby Hospital, Derby DE22 3NE, UK

3 Department of Sport and Health Sciences, College of Life and Environmental Sciences, University of Exeter, Exeter EX1 2LU, UK; c.s.deane@exeter.ac.uk

4 Living Systems Institute, University of Exeter, Stocker Road, Exeter EX4 4QD, UK

5 Research and Development, Abbott Nutrition, 18004 Granada, Spain; ricardo.rueda@abbott.com

6 Research and Development, Abbott Nutrition, Columbus, OH 43219, USA; suzette.pereira@abbott.com

* Correspondence: philip.atherton@nottingham.ac.uk (P.J.A.); beth.phillips@nottingham.ac.uk (B.E.P.)

+ These authors contributed equally to this work.

$\ddagger$ These authors contributed equally to this work.

Abstract: Postprandial macro- and microvascular blood flow and metabolic dysfunction manifest with advancing age, so vascular transmuting interventions are desirable. In this randomised, singleblind, placebo-controlled, crossover trial, we investigated the impact of the acute administration of green tea extract (GTE; containing 500 mg epigallocatechin-3-gallate) versus placebo (CON), alongside an oral nutritional supplement (ONS), on muscle macro- and microvascular, cerebral macrovascular (via ultrasound) and leg glucose/insulin metabolic responses (via arterialised/venous blood samples) in twelve healthy older adults ( $42 \%$ male, $74 \pm 1 \mathrm{y}$ ). GTE increased $m$. vastus lateralis microvascular blood volume (MBV) at 180 and $240 \mathrm{~min}$ after ONS (baseline: $1.0 \mathrm{vs.} 180 \mathrm{~min}$ : $1.11 \pm 0.02$ vs. $240 \mathrm{~min}: 1.08 \pm 0.04$, both $p<0.005)$, with MBV significantly higher than CON at $180 \mathrm{~min}(p<0.05)$. Neither the ONS nor the GTE impacted $m$. tibialis anterior perfusion $(p>0.05)$. Leg blood flow and vascular conductance increased, and vascular resistance decreased similarly in both conditions $(p<0.05)$. Small non-significant increases in brachial artery flow-mediated dilation were observed in the GTE only and middle cerebral artery blood flow did not change in response to GTE or CON $(p>0.05)$. Glucose uptake increased with the GTE only ( $0 \mathrm{~min}: 0.03 \pm 0.01$ vs. $35 \mathrm{~min}$ : $0.11 \pm 0.02 \mathrm{mmol} / \mathrm{min} / \mathrm{leg}, p=0.007)$; however, glucose area under the curve and insulin kinetics were similar between conditions ( $p>0.05$ ). Acute GTE supplementation enhances MBV beyond the effects of an oral mixed meal, but this improved perfusion does not translate to increased leg muscle glucose uptake in healthy older adults.

Keywords: green tea extract; epigallocatechin-3-gallate; blood flow; glucose metabolism; skeletal muscle

\section{Introduction}

Increased vascular resistance [1] and endothelial dysfunction [2] are both hallmarks of advancing age and are each central risk factors for cardiometabolic disease [3]. The ensuing reductions in muscle perfusion $(\sim 20-30 \%$ in limb conduit artery blood flow compared to 
younger adults $[4,5]$ ) have also been posited to play a role in the aetiology of sarcopenia (i.e., age-related muscle mass and functional decline [6]), which increases the risk of frailty [7], morbidity [8] and mortality [9] and thus represents a major global health problem. Indeed, blunted muscle microvascular blood flow responses are observed in older adults following anabolic stimuli (e.g., feeding) [10,11], and nutrient-induced increases in whole-limb perfusion are attenuated with advancing age [5]. These diminished vascular responses are hypothesised to contribute to age-related "anabolic resistance" to nutrition, via the attenuated delivery and/or utility of nutrients (e.g., amino acids) and hormones (e.g., insulin) to muscle [12], although it does not fully explain anabolic resistance, since enhancing microvascular blood flow does not improve muscle anabolism [13]. Nonetheless, the ability to preserve vascular function in lifelong exercisers [14] and improve vascular function in novice exercisers [15] demonstrates that vascular dysfunction is a modifiable, rather than inevitable, aspect of chronological ageing [11]. Therefore, determining nutraceutical strategies for maintaining/potentiating vascular and metabolic responses in older adults may have significant ramifications for reducing cardiovascular disease risk and could also play a role in the maintenance of muscle health.

Epidemiological evidence has demonstrated robust correlations between green tea consumption and protection against both cardiovascular and metabolic disease [16-18]. The benefits of green tea are largely attributed to the naturally occurring polyphenols, particularly epigallocatechin-3-gallate (EGCg), which belongs to the catechin family and accounts for $\sim 33-50 \%$ of the green tea solid $[3,19]$. At the molecular level, EGCg stimulates nitric oxide production in endothelial cells (similar to insulin [3]) primarily via the activation of endothelial nitric oxide synthase, PI3-K and Akt, resulting in nitric oxide (NO)-dependent vasodilation [3,20-22]. An array of pre-clinical data has directly shown that green tea/EGCg can promote vasodilation, attenuate vascular inflammation, prevent endothelial injury and ultimately enhance vascular function [22-24]. Compared to pre-clinical models, the corresponding effects of green tea have been less studied in humans [25]. However, from the available evidence, it has been shown that green tea-based supplements can improve endothelial dysfunction in smokers [26,27] and coronary artery disease patients [28], and can increase post-exercise blood flow in young trained men [25]. Further, the acute administration of EGCg has been shown to modulate cerebral blood flow in healthy humans [29], demonstrating the ability of green tea and/or its constituents to elicit multi-organ vascular responses.

The aforementioned green tea-induced enhancements in vascular function are the basis of the purported mechanisms underlying the subsequent improvements in insulin/glucose homeostasis, evidenced in pre-clinical models [21,30]. Should these synergistic cardiometabolic impacts of green tea be recapitulated in humans, they stand to significantly benefit health, since insulin resistance manifests with advancing age and has been shown to contribute to the development of sarcopenia [31]. Whilst there is a paucity of human data, a recent meta-analysis concluded that chronic green tea consumption may reduce fasting blood glucose levels [32], and acute supplement studies have shown green tea to improve glucose tolerance and insulin sensitivity [33], albeit not consistently [34] (and accompanying muscle perfusion measures were absent). Thus, whether green tea-induced improvements in vascular responses favourably impact insulin and glucose metabolism in healthy older adults remains to be elucidated.

Identifying efficacious nutraceuticals that impact brain, limb and skeletal muscle perfusion may improve the suboptimal glucose handling observed in ostensibly healthy older adults. Therefore, the aim of this study was to assess the impact of acute green tea extract (GTE) supplementation on oral feeding-induced changes on: (i) macrovascular (limb) blood flow, (ii) microvascular blood flow of the $m$. vastus lateralis and $m$. tibialis anterior, (iii) endothelial function, (iv) cerebral blood flow, and (v) metabolic responses in healthy older adults. 


\section{Materials and Methods}

\subsection{Ethical Approval}

All the study-associated risks and procedures were thoroughly explained to the volunteers and their written consent was obtained prior to their participation. This study was reviewed and approved by the University of Nottingham Faculty of Medicine and Health Sciences Research Ethics Committee (2-1704), was conducted in accordance with the Declaration of Helsinki, and was pre-registered at clinicaltrials.gov (NCT03213340).

\subsection{Volunteers and Study Design}

Healthy older adults ( $\geq 65$ years) were recruited from the local community for this randomised, single-blind, placebo-controlled, crossover trial. At the initial screening session, the volunteers' previous medical history was discussed with a clinician, which included habitual dietary intake and known food allergies. Volunteers were considered eligible for the study if they met the following inclusion criteria: (i) $\geq 65$ years; (ii) body mass index $18-30 \mathrm{~kg} / \mathrm{m}^{2}$; (iii) free from active metabolic disease with a clinically normal blood profile (liver and kidney function; complete blood count; $\mathrm{HbA} 1 \mathrm{c}<6 \%$ ); (iv) blood pressure $<160 / 100 \mathrm{mmHg}$; and (v) able to provide written informed consent. The exclusion criteria were: inability to adhere to the study protocol; performing regular formal exercise (or any other routine strenuous exercise) more than once a week; smoking; surgery within the past 3 months; cerebrovascular disease or active cardiovascular, respiratory, inflammatory bowel or renal disease; taking beta-adrenergic blocking agents; active malignancy or until confirmed remission; clotting dysfunction; a history of deep vein thrombosis; significant musculoskeletal or neurological disorders; a family history of early ( $<55$ years) death from cardiovascular disease; a known sensitivity to Sonovue ${ }^{\mathrm{TM}}$ contrast agent; a known allergy or intolerance to any of the study ingredients; and/or regularly taking over-the-counter supplements containing GTE. The volunteers also completed a short physical performance battery and a handgrip strength assessment during this screening session (Table 1). Eligible volunteers were enrolled in the study and were assigned subject numbers, which were randomly assigned to either placebo (control, CON) or GTE for the first study visit. The randomisation was performed using the simple online randomisation service 'Sealed Envelope' (Sealed Envelope Ltd., London, UK). In line with previous work detecting supplement-induced (and non-supplement-induced) changes in microvascular responses to feeding in $n=10-12$, a total of 12 volunteers were recruited for this study $[35,36]$.

Table 1. Volunteer characteristics (mean $\pm \mathrm{SD}$ ).

\begin{tabular}{cc}
\hline Parameter & Volunteers $(\boldsymbol{n = 1 2})$ \\
\hline Gender (\% males) & $42 \%$ \\
Age (year) & $74 \pm 1$ \\
Height (cm) & $168 \pm 13$ \\
Weight (kg) & $73.4 \pm 13.1$ \\
BMI (kg/m $\left.{ }^{2}\right)$ & $26.1 \pm 2.5$ \\
Lean mass (kg) & $45.7 \pm 10.5$ \\
Resting heart rate (bpm) & $62 \pm 6$ \\
Resting systolic blood pressure (mmHg) & $136 \pm 11$ \\
Resting diastolic blood pressure (mmHg) & $77 \pm 8$ \\
Grip strength (kg) & $27 \pm 8$ \\
SPPB & $9 \pm 2$ \\
\hline
\end{tabular}

BMI, body mass index; SPPB, short physical performance battery.

For the enrolled volunteers, this study included two experimental study visits separated by a 10-15 day "wash-out" period (Figure 1). The volunteers were instructed to refrain from taking medications that may impact blood flow on the day prior to and on the day of each study visit (e.g., angiotensin-converting enzyme inhibitors, decongestants) and from heavy exercise for $48 \mathrm{~h}$ prior to each study visit. On the day of testing, the volunteers arrived at 0900h fasted from 2200h the night before (water ad libitum) and had 
their lean leg mass measured with dual X-ray absorptiometry (DXA; Luna Prodigy II; GE Medical Systems, Little Chalfont, Buckinghamshire, UK) (study visit 1 only). Baseline measures of leg blood flow (LBF) via Doppler ultrasound, microvascular blood flow (MBF) via contrast-enhanced ultrasound (CEUS), endothelial function via flow-mediated dilation (FMD), and middle cerebral artery blood flow velocity via transcranial doppler (TCD) were then performed, and a baseline blood sample was taken. All the ultrasound measures were taken using a Philips iU22 ultrasound machine (Philips Healthcare, Reigate, UK). The volunteers were then provided with the study supplement (GTE or placebo) to consume orally, with an oral nutritional supplement (ONS) consumed 60 min later. Thereafter, Doppler, CEUS, FMD and TCD measures and blood samples were obtained periodically over a $4 \mathrm{~h}$ period (Figure 1).

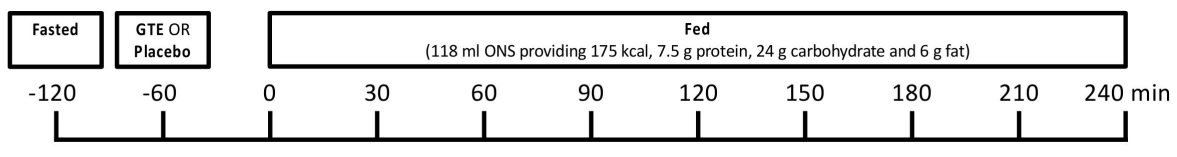

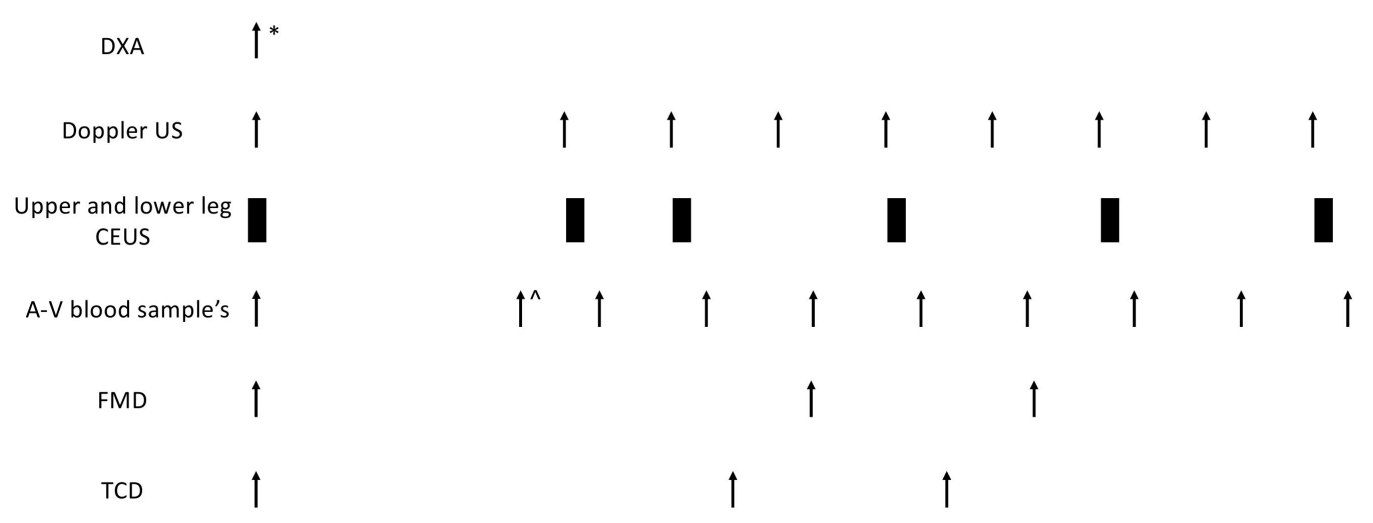

Figure 1. Schematic representation of the study protocol for experimental study visits 1 and 2 . Twelve healthy older adults were studied in a crossover design in a fasted state, and with and without green tea extract in a fed state (via oral nutritional supplement). ${ }^{*}$ indicates assessment was carried out during study visit 1 only, ${ }^{\wedge}$ indicates that the first blood draw occurred 15 min after the oral nutritional supplement. A-V, arterio-venous; CEUS, contrast-enhanced ultrasound; DXA, dual-energy X-ray absorptiometry; FMD, flow-mediated dilation; GTE, green tea extract; ONS, oral nutritional supplement; TCD, transcranial doppler; US, ultrasound.

\subsection{Study Supplements and ONS Feeding}

The volunteers were randomly assigned to receive either the GTE or placebo supplement in a crossover design. The placebo condition comprised four empty capsules matched for appearance to the GTE. The GTE condition comprised four capsules, each containing GTE $(300 \mathrm{mg})$ that itself contained $\sim 45 \%$ EGCg $(\sim 135 \mathrm{mg})$ in addition to other catechins (Sunphenon, 90D, Taiyo, Japan), thus delivering a total of $\sim 500 \mathrm{mg}$ EGCg). The $500 \mathrm{mg}$ EGCg dose was chosen as it is lower than doses ( 800 mg EGCg) shown to be safe and very well tolerated [37], but is slightly higher than doses ( 300 mg EGCg) shown to improve aspects of blood flow (e.g., FMD [28]) and glucose metabolism (e.g., fasting blood glucose [38]). It was therefore postulated to be a safe and effective acute dose. Since caffeine has been implicated in regulating vascular health [20], the GTE used was decaffeinated. In order to investigate whether GTE can enhance vascular responses beyond those achieved with mixed oral feeding, the volunteers consumed $118 \mathrm{~mL}$ of an ONS (Ensure Advance (Vanilla), Abbott, Zwolle, NE) providing $175 \mathrm{kcal}$ (7.5 g protein, $24 \mathrm{~g}$ carbohydrate and $6 \mathrm{~g}$ fat) exactly $60 \mathrm{~min}$ after consuming the supplement.

\subsection{Measurement of LBF Using Doppler Ultrasound}

As previously described [39], LBF was measured by using a Doppler ultrasound (iU22 ultrasound scanner, Phillips Healthcare, Reigate, Surrey, UK). In brief, a 17-5 MHz linear 
probe was positioned over the left common femoral artery to facilitate the assessment of LBF as vessel cross-sectional area $x$ mean velocity, over six cardiac cycles. To enhance the ultrasound signal, ultrasound gel was used and all the measurements were taken with the volunteer supine with no visual or aural stimuli. A mean of three measurements was made at every timepoint, dispersed across the study period. In accordance with other studies $[12,40]$, leg vascular conductance (LVC) was calculated as: LBF/mean arterial pressure (which was calculated as: ( $2 / 3$ diastolic blood pressure) $+(1 / 3$ systolic blood pressure)) and leg vascular resistance (LVR) was calculated as: mean arterial pressure/LBF.

\subsection{Measurement of MBF Using CEUS}

CEUS, as previously described in detail [41], allows the measurement of changes in MBF and its components: microvascular blood volume (MBV) and microvascular flow velocity (MFV). In brief, an iU22 ultrasound scanner (Phillips Healthcare, Reigate, Surrey, UK) was used to detect Sonovue ${ }^{\mathrm{TM}}$ microbubbles (Bracco, Milan, Italy) that were infused with an antecubital fossa vein. One L9-3 MHz linear probe was positioned on the $m$. vastus lateralis and another on the $m$. tibialis anterior to detect intravascular microbubble concentrations in both muscles. The microbubbles were disrupted using intermittent high mechanical index (MI) "flashes" with subsequent continuous low MI recordings measuring the rate of microbubble reappearance after each flash. The Sonovue ${ }^{\mathrm{TM}}$ was first infused at $2 \mathrm{~mL} / \mathrm{min}$ for $1 \mathrm{~min}$ and then $1 \mathrm{~mL} / \mathrm{min}$ for $3 \mathrm{~min}$ thereafter. At $2.5 \mathrm{~min}, 3 \times 30 \mathrm{~s}$ flash/replenishment recordings were performed across the last $90 \mathrm{~s}$ of this protocol at each CEUS timepoint. After each flash, a $0.48 \mathrm{~s}$ window was used to adjust for the non-contrast signal and for the rapid filling of larger conduit (non-exchange) vessels. The acoustic intensity of the insonated tissue in the post-flash period demonstrated a first order exponential association function with a rate constant that was proportional to MFV and a plateau proportional to MBV.

\subsection{Measurement of Endothelial Function and Cerebral Blood Flow}

FMD was used to assess endothelial function (right brachial artery) using standard methodology, according to the International Brachial Artery Reactivity Task Force guidelines [42]. In brief, after a baseline measurement of the brachial artery diameter for $1 \mathrm{~min}$ using a $17-5 \mathrm{MHz}$ linear probe, arterial occlusion distal to the brachial artery was induced using a blood pressure cuff (Hokanson, Bellevue, WA, USA) inflated to $200 \mathrm{mmHg}$ for $5 \mathrm{~min}$. The cuff was then deflated, and the dilation of the brachial artery assessed for a further $5 \mathrm{~min}$. Automated real-time arterial diameter measurements were generated through the Quipu Cardiovascular Suite FMD Studio (Quipu, Tuscany, Italy). FMD could not be recorded for two volunteers due to software failure (as such data is $n=10$ ).

TCD ultrasonography was used to measure middle cerebral artery blood flow velocity as an index of cerebrovascular function [43] using standard techniques [44,45]. In brief, with all the measures performed by the same technician using a $5-1 \mathrm{MHz}$ probe, the transtemporal window was located to measure middle cerebral artery (MCA) blood flow velocity (MFV). The depths of insonation were recorded so they could be duplicated during each volunteer's second study visit, with depths between $50-60 \mathrm{~mm}$. It was not possible to locate the transtemporal window in four volunteers (as such data is $n=8$ ).

\subsection{Blood Glucose and Plasma Insulin}

Glucose uptake/release was assessed using an arterio-venous (A-V) sampling approach. The blood glucose concentrations were measured (Glucose Analyser, YSI, Yellow Springs, $\mathrm{OH}, \mathrm{USA}$ ) across the leg by sampling arterialised (obtained via the "hot-hand" technique [46,47]) and venous bloods (using the Fick Principle). Plasma insulin concentrations were measured in venous blood using a high-sensitivity human insulin enzyme-linked immunosorbent assay (DRG Instruments $\mathrm{GmbH}$, Marburg, Germany), according to manufacturer's instructions. The total insulin and glucose responses to feeding for each volunteer 
were calculated using the area under the insulin/glucose concentration/time curve above baseline (with baseline equal to the concentration measured before supplement/feeding).

\subsection{Statistical Analysis}

Two-way repeated measures ANOVA with Sidak/Dunnett's multiple comparison analysis was used to determine time $\mathrm{x}$ supplement effects. To allow comparison between conditions, the CEUS data was normalised to baseline. The area under the curve (AUC) analysis was conducted on the blood glucose A-V balance and insulin data, with paired t-tests used to determine the supplements' effects. The data analysis was conducted using GraphPad Prism version 8 (GraphPad Software, San Diego, CA, USA), with data accepted as significant if $p<0.05$. The data are presented as mean \pm SEM.

\section{Results}

\section{1. $L B F, L V C$ and $L V R$}

LBF significantly increased from baseline in both conditions early in the fed phase (GTE: 0 min: $232.4 \pm 18.2$ vs. $55 \mathrm{~min}: 335.4 \pm 15.6 \mathrm{~mL} / \mathrm{min}, p=0.001$; CON: $0 \mathrm{~min}$ : $259.6 \pm 21.2$ vs. $85 \mathrm{~min}: 359.4 \pm 36.2 \mathrm{~mL} / \mathrm{min}, p=0.002)$, and was elevated at $235 \mathrm{~min}$ in both groups (GTE: 0 min: $232.4 \pm 18.2$ vs. $235 \mathrm{~min}: 331.1 \pm 23.6 \mathrm{~mL} / \mathrm{min}, p=0.002$; CON: 0 min: $259.6 \pm 21.2$ vs. $235 \mathrm{~min}: 342.1 \pm 41.2 \mathrm{~mL} / \mathrm{min}, p=0.016$ ) (Figure $2 \mathrm{~A})$. Interestingly, following the ONS, LBF was significantly above baseline at all timepoints in the GTE condition, but not for the $\mathrm{CON}$ condition, which displayed values that were no different to baseline at 175 and $205 \mathrm{~min}$ (Figure 2A).

LVC increased at $55 \mathrm{~min}$ in the GTE condition ( $0 \mathrm{~min}: 2.51 \pm 0.23$ vs. $55 \mathrm{~min}$ : $3.76 \pm 0.19 \mathrm{~mL} / \mathrm{min}, p=0.023$ ) and at $85 \mathrm{~min}$ in the CON condition ( $0 \mathrm{~min}: 2.65 \pm 0.22 \mathrm{vs}$. $85 \mathrm{~min}: 4.00 \pm 0.34 \mathrm{~mL} / \mathrm{min}, p=0.003)$, with both conditions returning to basal values at $235 \mathrm{~min}$ (GTE: 0 min: $2.51 \pm 0.23$ vs. $235 \mathrm{~min}: 3.41 \pm 0.35 \mathrm{~mL} / \mathrm{min}, p=0.125$; CON: $0 \mathrm{~min}$ : $2.65 \pm 0.22$ vs. $235 \mathrm{~min}: 3.60 \pm 0.45 \mathrm{~mL} / \mathrm{min}, p=0.111$ ).

LVR decreased in both conditions, with the onset occurring at $55 \mathrm{~min}$ in the GTE condition ( $0 \mathrm{~min}: 0.44 \pm 0.05$ vs. $55 \mathrm{~min}: 0.27 \pm 0.01 \mathrm{~mL} / \mathrm{min}, p<0.0001)$, which preceded the LVR decline in the CON condition, which occurred at $85 \mathrm{~min}(0 \mathrm{~min}: 0.41 \pm 0.04$ vs. $85 \mathrm{~min}: 0.27 \pm 0.02 \mathrm{~mL} / \mathrm{min}, p=0.001)$. LVR remained depressed throughout all the subsequent timepoints in the GTE condition, whereas LVR returned to baseline by $175 \mathrm{~min}$ in the CON condition ( 0 min: $0.41 \pm 0.04$ vs. $175 \mathrm{~min}: 0.31 \pm 0.02 \mathrm{~mL} / \mathrm{min}, p=0.06)$ (Figure 2C). There were no significant differences between conditions at any timepoint for LBF, LVC or LVR.

A

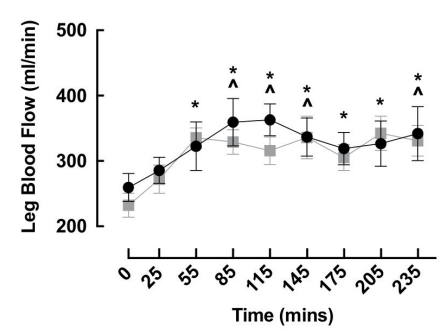

B

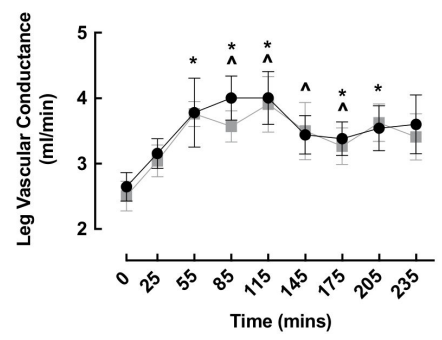

C

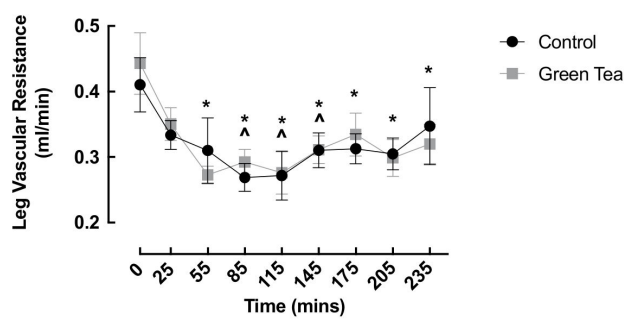

Figure 2. The impact of oral nutritional supplement feeding with/without green tea extract on leg blood flow (A), vascular conductance $(\mathbf{B})$ and vascular resistance $(\mathbf{C})$ in healthy older adults. ^ denotes significant difference from control baseline $(p$ $<0.05) ;{ }^{*}$ denotes significant difference from green tea extract baseline $(p<0.05)$.

\section{2. $M B V, M F V$ and $M B F$}

In the $m$. vastus lateralis, the GTE condition elicited a significant increase from baseline in MBV responses to the ONS, with this increase evident at 180 and 240 min post-meal (baseline: 1.0 vs. $180 \mathrm{~min}: 1.11 \pm 0.02$ vs. $240 \mathrm{~min}: 1.08 \pm 0.04, p=0.002$ ). In the CON condition, MBV significantly increased from baseline at only $240 \mathrm{~min}$ post-meal (baseline: 
1.0 vs. 240 min: $1.07 \pm 0.02, p=0.013)$. MBV was significantly higher in the GTE condition versus the CON condition at $180 \mathrm{~min}$ post-meal (GTE: $1.11 \pm 0.02$ vs. CON: $1.04 \pm 0.02$, $p=0.014)$ (Figure 3A).

MFV in the $m$. vastus lateralis only increased in the CON condition at $180 \mathrm{~min}$ (baseline: 1.0 vs 180 min: $1.62 \pm 0.24, p=0.003)$; however, there was no significant difference between the conditions at any timepoint (Figure 3B). Similarly, MBF only increased in the CON condition at $180 \mathrm{~min}$ post-meal (baseline: 1.0 vs $180 \mathrm{~min}: 1.70 \pm 0.27, p=0.001$ ) (Figure 3C). This was largely driven by the observed increase in MFV (Figure 3B).

For the $m$. tibialis anterior, there was no significant change within or between conditions at any timepoint for MBV, MFV or MBF (Figure 3D-F).

m. vastus lateralis

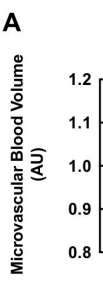

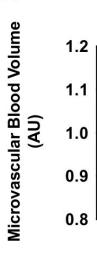

D

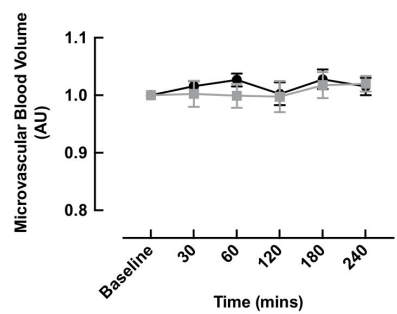

B

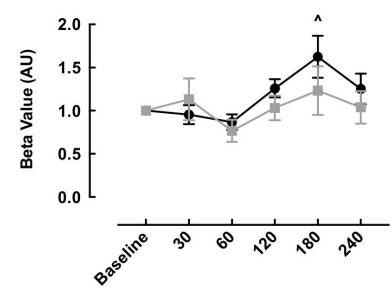

E

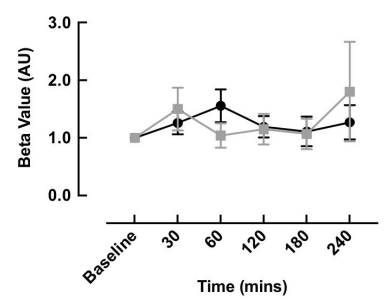

c

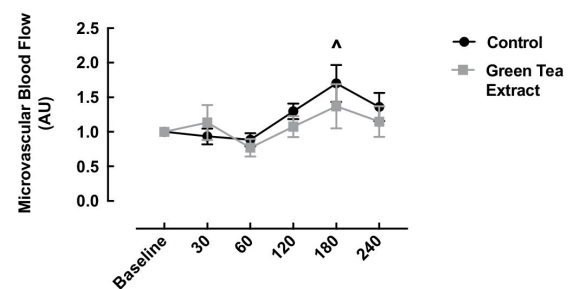

$\mathbf{F}$

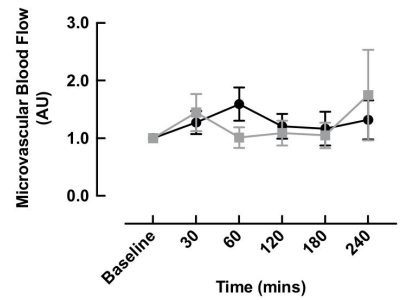

Figure 3. The impact of oral nutritional supplement feeding with/without green tea extract on microvascular blood volume $(\mathbf{A}, \mathbf{D})$, microvascular flow velocity $(\mathbf{B}, \mathbf{E})$ and microvascular blood flow $(\mathbf{C}, \mathbf{F})$ in the $m$. vastus lateralis $(\mathbf{A}-\mathbf{C})$ and $m$. tibialis anterior (D-F) of healthy older adults. $\sim$ denotes a significant difference between groups $(p<0.05)$; ^ denotes significant difference from control baseline $(p<0.05) ;{ }^{*}$ denotes significant difference from green tea extract baseline $(p<0.05)$.

\subsection{FMD and TCD}

Although there was a numerical increase in FMD in the GTE condition at 100 and $160 \mathrm{~min}$ following the ONS (GTE: baseline: $5.36 \pm 1.15$ vs. $100 \mathrm{~min}: 6.83 \pm 1.10$ vs. $160 \mathrm{~min}$ : $6.12 \pm 1.52, p>0.05)$, which was potentially indicative of improved endothelial function, the increases at neither timepoint were statistically significant, nor were there any significant differences between the groups at any timepoint (Figure 4A). There was no significant effect of the ONS with or without GTE on the TCD measurements at any timepoint, signifying no change in cerebral blood flow (Figure $4 \mathrm{~B}$ ).

A

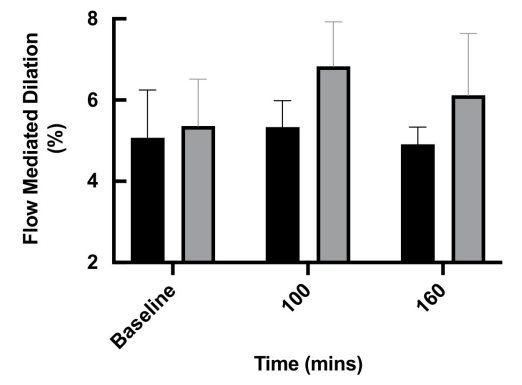

B

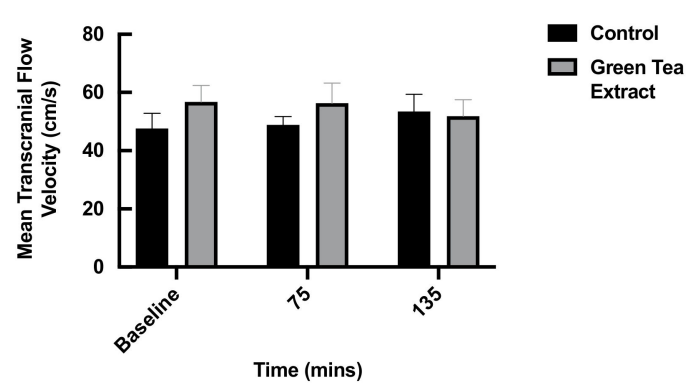

Figure 4. Effect of oral nutritional supplement feeding with/without green tea extract on (A) flow mediated dilation $(n=10$ per condition) and $(\mathbf{B})$ transcranial blood flow ( $n=8$ per condition) in healthy older adults. 


\subsection{Blood Glucose and Plasma Insulin}

Arterial and venous glucose both significantly increased in the early post-feeding phase in both the GTE and CON conditions, returning to basal values by $155 \mathrm{~min}$ in both conditions (Figure 5A,B). Interestingly, in the GTE condition, arterial glucose was significantly reduced from baseline at $215 \mathrm{~min}$ and $245 \mathrm{~min}$ (Figure $5 \mathrm{~A}$ ) and venous glucose was significantly reduced at $245 \mathrm{~min}$ (Figure 5B). No significant difference was observed between the conditions at any timepoint, and arterial and venous AUC was no different between the conditions (data not shown).

A
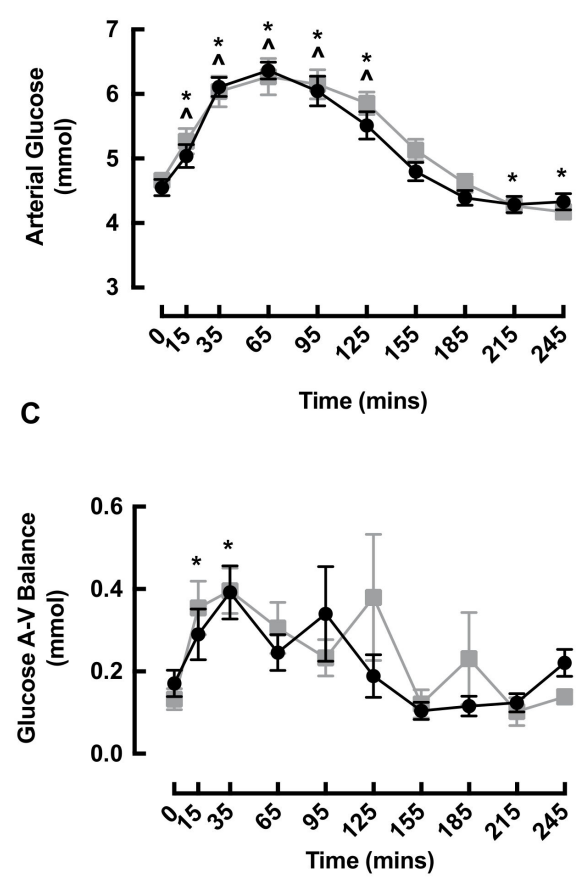

E

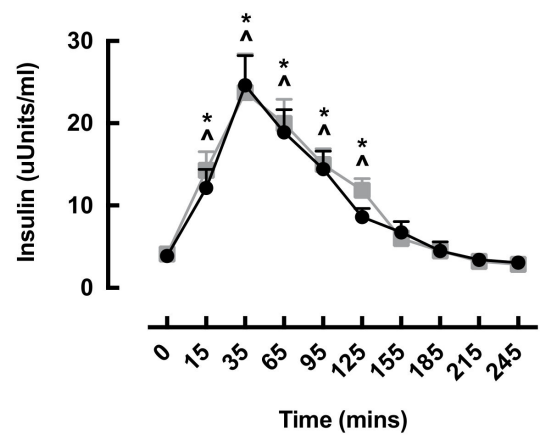

B
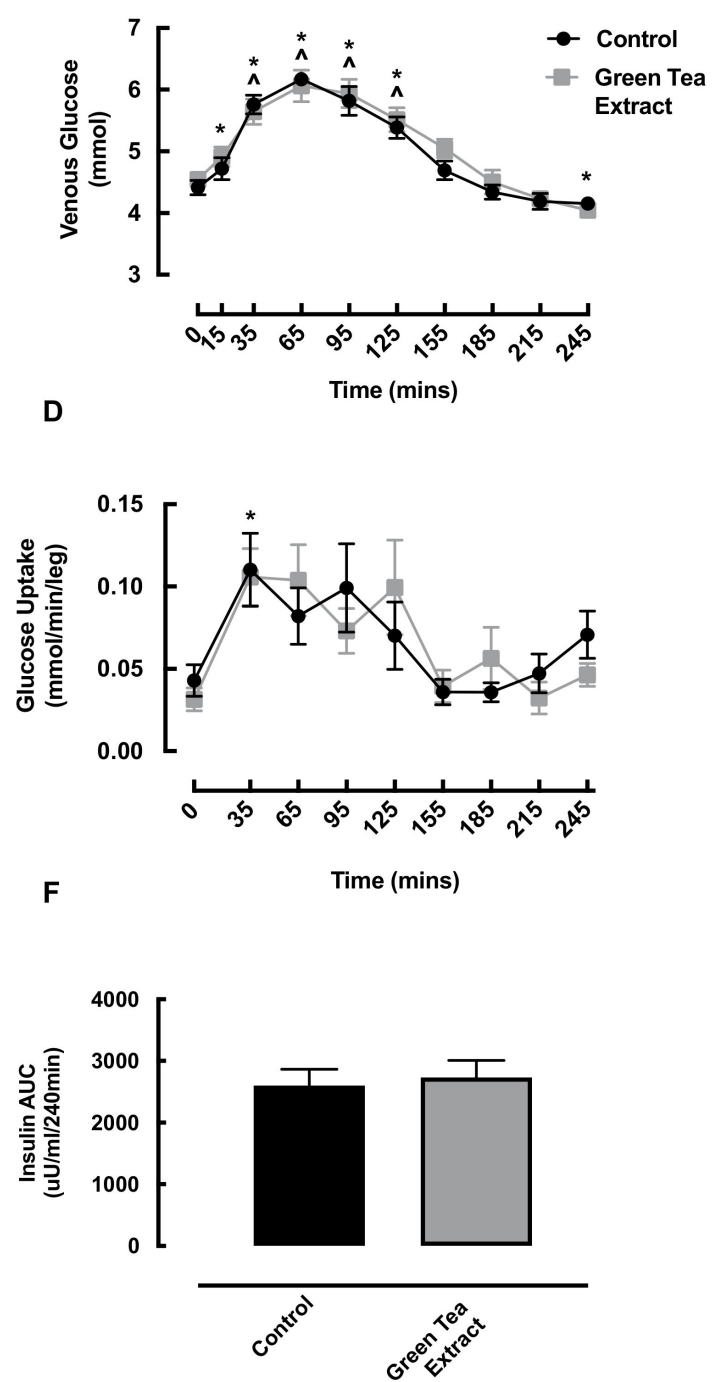

Figure 5. Changes in arterial glucose (A), venous glucose (B), glucose A-V balance (C), glucose uptake (D), insulin (E) and insulin area under the curve (F) in healthy older adults with/without green tea extract following oral nutritional supplement feeding. ' denotes significant difference from control baseline $(p<0.05) ;{ }^{*}$ denotes significant difference from green tea extract baseline $(p<0.05)$. AUC, area under the curve; $\mathrm{A}-\mathrm{V}$, arterio-venous.

Glucose A-V balance increased at 15 and $35 \mathrm{~min}$ in the GTE condition only ( $0 \mathrm{~min}$ : $0.13 \pm 0.03$ vs. $15 \mathrm{~min}: 0.35 \pm 0.06$ vs. $35 \mathrm{~min}: 0.40 \pm 0.06 \mathrm{mmol}$, both $p<0.05)$; however, there was no significant difference between the conditions for glucose A-V balance at any timepoint (Figure 5C), or for glucose AUC (data not shown). Glucose uptake was increased in the GTE condition at $35 \mathrm{~min}$ only (GTE: $0 \mathrm{~min}$ : $0.03 \pm 0.01$ vs. $35 \mathrm{~min}$ : $0.11 \pm 0.02 \mathrm{mmol} / \mathrm{min} / \mathrm{leg}, p=0.007)$; however, there was no significant difference be- 
tween the conditions at any time point for glucose uptake (Figure 5D) or glucose uptake AUC (data not shown).

As expected, plasma insulin significantly increased from baseline in both conditions early post-feeding, returning to basal values by $155 \mathrm{~min}$ (Figure 5E). There was no significant difference between the conditions at any timepoint for insulin or insulin AUC (Figure 5E,F).

\section{Discussion}

We investigated whether acute GTE supplementation prior to oral mixed macronutrient feeding would modify vascular and subsequent metabolic responses in healthy older adults who have no known impairments in metabolic status. We found that acute GTE increased micro- but not macro-, endothelial or cerebral vascular responses to ONS; however, enhanced microvascular perfusion did not translate into improved insulin/glucose responses.

To our knowledge, this is the first study to assess the acute impact of GTE supplementation on leg muscle perfusion in healthy older adults. Our primary finding was that a high dose of GTE (containing 500 mg of EGCg) can enhance the effect of a small mixed macronutrient meal by increasing MBV in the $m$. vastus lateralis of older healthy men and women. This demonstrates that the impact of GTE goes beyond the effects of the feeding-related insulin response, having the ability to impact vasodilation of the muscle capillaries therein increasing blood volume, and thus potentially the concentration of nutrients, in the muscle tissue. Similar to other flavonoids (e.g., cocoa flavanols [48]), it has been previously shown that green tea constituents can induce NO production in the endothelial cells, leading to vasodilation [20-22], which is the likely mechanism underlying the responses observed herein. Interestingly, increased MBV above that of the ONS was only observed at a late postprandial timepoint ( $180 \mathrm{~min})$, by which time net essential amino acid uptake has normally returned to postabsorptive levels [49]. Therefore, it is likely that this response reflects late capillary recruitment and so is not expected to impact upon essential amino acid-driven increases in muscle protein synthesis, which abate $\sim 2-3 \mathrm{~h}$ post-feeding [50]. Indeed, some of our previous data support this notion, whereby we found that early but not later postprandial capillary recruitment supports feeding-induced protein accretion via the delivery of EAA to the muscle [49]. As such, the question that still remains is, what are the physiological implications of enhanced 'late' vascular responses following acute GTE? Considering enhanced microvascular flow still represents increased nutrient, hormone and oxygen delivery to muscle (despite occurring after the "anabolic window" [50]), it is reasonable to hypothesise that such acute responses may accrue and develop into adaptations observed with chronic supplementation. For example, chronic GTE supplementation has been shown to facilitate recovery from strenuous exercise [51], improve endurance capacity via enhanced metabolic capacity and fatty acid utilisation [52] and attenuate age and diet-related muscle decline (albeit in pre-clinical models) [53-55], which may be related to enhanced MBV. Thus, like certain other plant flavonoids [35], we expect that GTE has important effects aside from acute protein anabolism, in the form of supporting physiological adaptations towards improving muscle health.

We also investigated MBF response in the $m$. tibialis anterior, a more oxidative and capillary-dense muscle ( $70 \%$ type I fibres [56]) compared to the $m$. vastus lateralis [57], to see whether GTE is more beneficial in this muscle due to the potential for greater capillary recruitment. However, we observed no effect of GTE or the ONS on MBV in this muscle, suggesting that neither EGCg nor insulin impact the delivery of nutrients/hormones/oxygen in the $m$. tibialis anterior. However, as this is, to our knowledge, the first attempt to assess the effects of GTE in the $m$. tibialis anterior, we postulate that it is plausible that the smaller muscle size and thus vascular network of the $m$. tibialis anterior (compared to the $m$. vastus lateralis) renders potentially impactful changes smaller and harder to detect, and so our findings require validation in larger cohort clinical trials. 
Despite enhancements in MBV, we observed no impact of GTE on other microvascular components, namely MFV and MBF, in the $m$. vastus lateralis or in the $m$. tibialis anterior. This, however, does not necessarily negate or lessen the efficacy of GTE for enhancing microvascular perfusion, since MBV (as opposed to other microvascular components) is confirmed to represent capillary perfusion [58,59]. It is also possible that longer-term feeding studies are needed to elucidate the effects of GTE on MFV, since MFV is dependent on the dilation of the resistance arterioles that are upstream of the terminal arterioles and capillaries. Similarly, there was no impact of GTE on macrovascular blood flow, although LBF, LVC and LVR were modulated by the ONS, suggesting that macrovascular-femoral artery flow is primarily driven by the insulin response to nutrition. Supporting our data, $\mathrm{Ng}$ et al. demonstrated that EGCg provision stimulated micro- but not macrovascular blood flow in rodents, leading the authors of that work to suggest that the vascular actions of EGCg (i.e., micro- vs. macrovascular) may be concentration-dependent [21]. As such, dose-response supplementation studies are needed to determine the efficacy of GTE on different aspects of human muscle blood flow.

Chronic supplementation studies have demonstrated that green tea and green tea catechins improve endothelial function in various clinical populations $[27,60]$, with acute green tea supplementation also shown to clinically improve endothelial function [61]. Therefore, we employed FMD to investigate the impact of acute GTE (in the context of a mixed ONS) on endothelial function in our older adult cohort. Although we observed a numerical increase in FMD in the GTE condition, particularly at 100 min post-feeding, this was not significantly different, statistically, from the baseline or the control. Interestingly, Lorenz et al. found that $200 \mathrm{mg}$ EGCg provided as part of a green tea beverage improved FMD in healthy men, but $200 \mathrm{mg}$ EGCg provided as GTE or isolated EGCg did not [62]. The authors suggest that the caffeine within green tea that may be responsible for eliciting changes in FMD, as opposed to EGCg [20]. However, another study demonstrated the benefits of green tea (containing caffeine) for FMD but failed to demonstrate any benefit of caffeine alone [63]. The GTE used herein was purposefully decaffeinated to avoid the confounding physiological effects of caffeine, and yet a numerical increase in FMD was still observed. Considering EGCg has been shown to have dose-dependent effects on vasodilation in rodents [21], it could be that larger acute doses of GTE may significantly enhance endothelial function measured via FMD. Whilst we provided a larger dose of EGCg than is typically present in a single cup of green tea (i.e., $500 \mathrm{mg}$ vs. 50-100 mg EGCg [64]), it is possible that more optimal GTE dosing strategies may be required to acutely enhance endothelial function. It is also possible that the chronic use of GTE is required to benefit endothelial function, since green tea containing $500 \mathrm{mg}$ catechins was shown to enhance forearm blood flow compared to lower doses of catechins (80 mg) following chronic use [27]. It is also possible that our small number of volunteers precluded statistical significance, thus requiring larger clinical trials to confirm/refute the acute effects of GTE on FMD.

With regard to cerebral blood flow, we found no effect of GTE or the ONS on the TCD measurements, indicating that EGCg and/or insulin does not modulate cerebral blood flow and thus the delivery of metabolic substrates to the brain, at least in ostensibly healthy older adults. An increase in cerebral blood flow may be considered advantageous, particularly within the current population of older adults who are at a greater risk of cardiovascular and neurovascular disease, since cerebral blood flow is positively associated with cognitive performance [65]. However, among the limited available evidence to date, Wightman et al. found that an acute dose of $135 \mathrm{mg}$ EGCg actually reduced cerebral blood flow when measured via near-infrared spectroscopy [29]. They postulated that the observed reduction may reflect a reduced requirement of blood flow due to improvements in other aspects of brain function by unidentified features and/or another unmeasured mechanism compensating for reduced cerebral blood flow [29]. It is clear that further clinical trials are required to clarify the current lack of consensus regarding whether GTE modulates cerebral blood flow. 
Finally, we determined whether GTE-induced increases in perfusion translated into enhanced glucose metabolism/uptake, a valid area for investigation considering glucose uptake is partially mediated by microvascular responses [66] and since chronic green tea supplementation decreased fasting blood glucose levels in type 2 diabetics [38]. Despite the presence of a GTE-induced increase in MBV, we did not observe any effects of GTE on insulin/glucose kinetics. Whilst this may initially seem surprising, we assessed the acute metabolic impacts of GTE in older healthy adults, whereas pre-existing supportive evidence is largely derived from pre-clinical and/or chronic studies (e.g., [67,68]). It should also be noted that leg A-V balance reflects all the tissues within the leg, whereas we only observed an increase in $m$. vastus lateralis MBV. It is therefore possible that we did not detect metabolic changes that may have occurred in individual muscles. Nonetheless, in line with our data, others have shown that acute EGCg infusion stimulated microvascular perfusion without altering whole-body or muscle glucose uptake, albeit in rodents [21]. Interestingly, the chronic provision of green tea/EGCg increases glucose uptake and promotes GLUT4 translocation in rodents [67]. This is likely mediated via the PI3-K/Akt [69] and/or AMPK [70] pathway, as demonstrated in cultured myotubes, and so EGCg is purported to demonstrate insulin-mimetic effects (although direct evidence of insulin receptor activation is lacking [71]), at least in the chronic context. Thus, chronic supplementation studies are warranted to determine whether GTE can elicit vascular-mediated glucose handling benefits in older healthy adults.

The potential limitations of this study warrant comment. First, the exact bioavailability of the GTE is not known. The GTE was delivered as a powder in a capsule and administered $60 \mathrm{~min}$ prior to the ONS to account for the previously reported absorption kinetics, which demonstrated a peak in plasma catechins 60 min following the consumption of encapsulated green tea [72]. Based on this, we speculated that the administration of GTE $60 \mathrm{~min}$ before the ONS would allow the peak catechin levels to coincide with the insulin response to the meal, thus maximising its impact on perfusion. Furthermore, similar oral EGCg supplementation led to detectable increases in human plasma EGCg [73], demonstrating bioavailability. Second, we acknowledge that by recruiting healthy older adults only (i.e., no pre-existing disease/comorbidities), our study population may not be truly representative of the older population, particularly considering the prevalence of comorbidities and associated polypharmacy in older age [74].

\section{Conclusions}

Acute GTE supplementation significantly increases microvascular perfusion, but does not affect macrovascular perfusion, endothelial function or cerebral blood flow beyond the effects of a mixed macronutrient meal in healthy older adults. However, enhanced MBV did not impact insulin/glucose metabolism. Oral GTE is well tolerated and therefore offers a safe and efficacious nutraceutical intervention for potentiating muscle perfusion, and thus nutrient/hormone/oxygen delivery, in healthy older adults.

Author Contributions: S.L.P., R.R., B.E.P. and P.J.A. conceptualised the study; U.S.U.D., T.S.S. and A.G. performed the studies and were responsible for sample collection; U.S.U.D. and T.S.S. performed the laboratory analysis; S.L.P., C.S.D., B.E.P. and P.J.A. analyzed and visualised the data; C.S.D., B.E.P. and P.J.A. drafted the manuscript. U.S.U.D., T.S.S., C.S.D., K.S., A.G., J.N.L., J.P.W., R.R., S.L.P., B.E.P. and P.J.A. reviewed and edited the manuscript. All authors have read and agreed to the published version of the manuscript.

Funding: This work was co-funded by Abbott Nutrition (US). This work was also supported by the Medical Research Council (grant number MR/P021220/1) as part of the MRC-Versus Arthritis Centre for Musculoskeletal Ageing Research awarded to the Universities of Nottingham and Birmingham, and also by the NIHR Nottingham Biomedical Research Centre. CSD acknowledges support from the Medical Research Council (grant number MR/T026014/1). 
Institutional Review Board Statement: The study was conducted according to the guidelines of the Declaration of Helsinki and approved by the University of Nottingham Faculty of Medicine and Health Sciences Research Ethics Committee (2-1704).

Informed Consent Statement: Informed consent was obtained from all the subjects involved in the study.

Data Availability Statement: The data presented in this study are available on reasonable request from the corresponding author.

Acknowledgments: The authors would like to thank the participants for dedicating their time to completing this study.

Conflicts of Interest: S.L.P. and R.R. are employees of Abbott Nutrition.

\section{References}

1. Lawrenson, L.; Poole, J.G.; Kim, J.; Brown, C.; Patel, P.; Richardson, R.S. Vascular and metabolic response to isolated small muscle mass exercise: Effect of age. Am. J. Physiol. Heart Circ. Physiol. 2003, 285, H1023-H1031. [CrossRef] [PubMed]

2. DeSouza, C.A.; Shapiro, L.F.; Clevenger, C.M.; Dinenno, F.A.; Monahan, K.D.; Tanaka, H.; Seals, D.R. Regular aerobic exercise prevents and restores age-related declines in endothelium-dependent vasodilation in healthy men. Circulation 2000, 102, 1351-1357. [CrossRef] [PubMed]

3. Keske, M.A.; Ng, H.L.; Premilovac, D.; Rattigan, S.; Kim, J.A.; Munir, K.; Yang, P.; Quon, M.J. Vascular and metabolic actions of the green tea polyphenol epigallocatechin gallate. Curr. Med. Chem. 2015, 22, 59-69. [CrossRef] [PubMed]

4. Donato, A.J.; Uberoi, A.; Wray, D.W.; Nishiyama, S.; Lawrenson, L.; Richardson, R.S. Differential effects of aging on limb blood flow in humans. Am. J. Physiol. Heart Circ. Physiol. 2006, 290, H272-H278. [CrossRef] [PubMed]

5. Skilton, M.R.; Lai, N.T.; Griffiths, K.A.; Molyneaux, L.M.; Yue, D.K.; Sullivan, D.R.; Celermajer, D.S. Meal-related increases in vascular reactivity are impaired in older and diabetic adults: Insights into roles of aging and insulin in vascular flow. Am. J. Physiol. Heart Circ. Physiol. 2005, 288, H1404-H1410. [CrossRef]

6. Mitchell, W.K.; Williams, J.; Atherton, P.; Larvin, M.; Lund, J.; Narici, M. Sarcopenia, dynapenia, and the impact of advancing age on human skeletal muscle size and strength; a quantitative review. Front. Physiol. 2012, 3, 260. [CrossRef] [PubMed]

7. Luukinen, H.; Koski, K.; Laippala, P.; Kivela, S.L. Factors predicting fractures during falling impacts among home-dwelling older adults. J. Am. Geriatr. Soc. 1997, 45, 1302-1309. [CrossRef]

8. Cruz-Jentoft, A.J.; Baeyens, J.P.; Bauer, J.M.; Boirie, Y.; Cederholm, T.; Landi, F.; Martin, F.C.; Michel, J.P.; Rolland, Y.; Schneider, S.M.; et al. Sarcopenia: European consensus on definition and diagnosis: Report of the European Working Group on Sarcopenia in Older People. Age Ageing 2010, 39, 412-423. [CrossRef]

9. Laukkanen, P.; Heikkinen, E.; Kauppinen, M. Muscle strength and mobility as predictors of survival in 75-84-year-old people. Age Ageing 1995, 24, 468-473. [CrossRef]

10. Dunford, E.C.; Au, J.S.; Devries, M.C.; Phillips, S.M.; MacDonald, M.J. Cardiovascular aging and the microcirculation of skeletal muscle: Using contrast-enhanced ultrasound. Am. J. Physiol. Heart Circ. Physiol. 2018, 315, H1194-H1199. [CrossRef]

11. Mitchell, W.K.; Phillips, B.E.; Williams, J.P.; Rankin, D.; Smith, K.; Lund, J.N.; Atherton, P.J. Development of a new Sonovue contrast-enhanced ultrasound approach reveals temporal and age-related features of muscle microvascular responses to feeding. Physiol. Rep. 2013, 1, e00119. [CrossRef]

12. Phillips, B.; Williams, J.; Atherton, P.; Smith, K.; Hildebrandt, W.; Rankin, D.; Greenhaff, P.; Macdonald, I.; Rennie, M.J. Resistance exercise training improves age-related declines in leg vascular conductance and rejuvenates acute leg blood flow responses to feeding and exercise. J. Appl. Physiol. 2012, 112, 347-353. [CrossRef] [PubMed]

13. Phillips, B.E.; Atherton, P.J.; Varadhan, K.; Wilkinson, D.J.; Limb, M.; Selby, A.L.; Rennie, M.J.; Smith, K.; Williams, J.P. Pharmacological enhancement of leg and muscle microvascular blood flow does not augment anabolic responses in skeletal muscle of young men under fed conditions. Am. J. Physiol. Endocrinol. Metab. 2014, 306, E168-E176. [CrossRef]

14. Gioscia-Ryan, R.A.; Clayton, Z.S.; Zigler, M.C.; Richey, J.J.; Cuevas, L.M.; Rossman, M.J.; Battson, M.L.; Ziemba, B.P.; Hutton, D.A.; VanDongen, N.S.; et al. Lifelong voluntary aerobic exercise prevents age-and Western diet- induced vascular dysfunction, mitochondrial oxidative stress and inflammation in mice. J. Physiol. 2020, 599, 911-925. [CrossRef] [PubMed]

15. Seals, D.R.; Nagy, E.E.; Moreau, K.L. Aerobic exercise training and vascular function with ageing in healthy men and women. J. Physiol. 2019, 597, 4901-4914. [CrossRef] [PubMed]

16. Pang, J.; Zhang, Z.; Zheng, T.; Yang, Y.J.; Li, N.; Bai, M.; Peng, Y.; Zhang, J.; Li, Q.; Zhang, B. Association of green tea consumption with risk of coronary heart disease in Chinese population. Int. J. Cardiol. 2015, 179, 275-278. [CrossRef] [PubMed]

17. Babu, P.V.; Liu, D. Green tea catechins and cardiovascular health: An update. Curr. Med. Chem. 2008, 15, 1840-1850. [CrossRef]

18. Iso, H.; Date, C.; Wakai, K.; Fukui, M.; Tamakoshi, A.; Group, J.S. The relationship between green tea and total caffeine intake and risk for self-reported type 2 diabetes among Japanese adults. Ann. Intern. Med. 2006, 144, 554-562. [CrossRef] [PubMed]

19. Lin, Y.S.; Tsai, Y.J.; Tsay, J.S.; Lin, J.K. Factors affecting the levels of tea polyphenols and caffeine in tea leaves. J. Agric. Food Chem. 2003, 51, 1864-1873. [CrossRef] 
20. Lorenz, M.; Urban, J.; Engelhardt, U.; Baumann, G.; Stangl, K.; Stangl, V. Green and black tea are equally potent stimuli of NO production and vasodilation: New insights into tea ingredients involved. Basic Res. Cardiol. 2009, 104, 100-110. [CrossRef] [PubMed]

21. Ng, H.L.H.; Premilovac, D.; Rattigan, S.; Richards, S.M.; Muniyappa, R.; Quon, M.J.; Keske, M.A. Acute vascular and metabolic actions of the green tea polyphenol epigallocatechin 3-gallate in rat skeletal muscle. J. Nutr. Biochem. 2017, 40, 23-31. [CrossRef]

22. Kim, J.A.; Formoso, G.; Li, Y.; Potenza, M.A.; Marasciulo, F.L.; Montagnani, M.; Quon, M.J. Epigallocatechin gallate, a green tea polyphenol, mediates NO-dependent vasodilation using signaling pathways in vascular endothelium requiring reactive oxygen species and Fyn. J. Biol. Chem. 2007, 282, 13736-13745. [CrossRef]

23. Lorenz, M.; Wessler, S.; Follmann, E.; Michaelis, W.; Dusterhoft, T.; Baumann, G.; Stangl, K.; Stangl, V. A constituent of green tea, epigallocatechin-3-gallate, activates endothelial nitric oxide synthase by a phosphatidylinositol-3-OH-kinase-, cAMP-dependent protein kinase-, and Akt-dependent pathway and leads to endothelial-dependent vasorelaxation. J. Biol. Chem. 2004, 279, 6190-6195. [CrossRef] [PubMed]

24. Potenza, M.A.; Marasciulo, F.L.; Tarquinio, M.; Tiravanti, E.; Colantuono, G.; Federici, A.; Kim, J.A.; Quon, M.J.; Montagnani, M. EGCG, a green tea polyphenol, improves endothelial function and insulin sensitivity, reduces blood pressure, and protects against myocardial I/R injury in SHR. Am. J. Physiol. Endocrinol. Metab. 2007, 292, E1378-E1387. [CrossRef] [PubMed]

25. Fox, C.D.; Garner, C.T.; Mumford, P.W.; Beck, D.T.; Roberts, M.D. Higher doses of a green tea-based supplement increase post-exercise blood flow following an acute resistance exercise bout in recreationally resistance-trained college-aged men. J. Int. Soc. Sports Nutr. 2020, 17, 27. [CrossRef]

26. Nagaya, N.; Yamamoto, H.; Uematsu, M.; Itoh, T.; Nakagawa, K.; Miyazawa, T.; Kangawa, K.; Miyatake, K. Green tea reverses endothelial dysfunction in healthy smokers. Heart 2004, 90, 1485-1486. [CrossRef] [PubMed]

27. Oyama, J.; Maeda, T.; Kouzuma, K.; Ochiai, R.; Tokimitsu, I.; Higuchi, Y.; Sugano, M.; Makino, N. Green tea catechins improve human forearm endothelial dysfunction and have antiatherosclerotic effects in smokers. Circ. J. 2010, 74, 578-588. [CrossRef] [PubMed]

28. Widlansky, M.E.; Hamburg, N.M.; Anter, E.; Holbrook, M.; Kahn, D.F.; Elliott, J.G.; Keaney, J.F., Jr.; Vita, J.A. Acute EGCG supplementation reverses endothelial dysfunction in patients with coronary artery disease. J. Am. Coll. Nutr. 2007, 26, 95-102. [CrossRef] [PubMed]

29. Wightman, E.L.; Haskell, C.F.; Forster, J.S.; Veasey, R.C.; Kennedy, D.O. Epigallocatechin gallate, cerebral blood flow parameters, cognitive performance and mood in healthy humans: A double-blind, placebo-controlled, crossover investigation. Hum. Psychopharmacol. 2012, 27, 177-186. [CrossRef]

30. Jang, H.J.; Ridgeway, S.D.; Kim, J.A. Effects of the green tea polyphenol epigallocatechin-3-gallate on high-fat diet-induced insulin resistance and endothelial dysfunction. Am. J. Physiol. Endocrinol. Metab. 2013, 305, E1444-E1451. [CrossRef] [PubMed]

31. Cleasby, M.E.; Jamieson, P.M.; Atherton, P.J. Insulin resistance and sarcopenia: Mechanistic links between common co-morbidities. J. Endocrinol. 2016, 229, R67-R81. [CrossRef]

32. Kondo, Y.; Goto, A.; Noma, H.; Iso, H.; Hayashi, K.; Noda, M. Effects of Coffee and Tea Consumption on Glucose Metabolism: A Systematic Review and Network Meta-Analysis. Nutrients 2018, 11, 48. [CrossRef] [PubMed]

33. Venables, M.C.; Hulston, C.J.; Cox, H.R.; Jeukendrup, A.E. Green tea extract ingestion, fat oxidation, and glucose tolerance in healthy humans. Am. J. Clin. Nutr. 2008, 87, 778-784. [CrossRef]

34. Josic, J.; Olsson, A.T.; Wickeberg, J.; Lindstedt, S.; Hlebowicz, J. Does green tea affect postprandial glucose, insulin and satiety in healthy subjects: A randomized controlled trial. Nutr. J. 2010, 9, 63. [CrossRef] [PubMed]

35. Sian, T.S.; Din, U.S.U.; Deane, C.S.; Smith, K.; Gates, A.; Lund, J.N.; Williams, J.P.; Rueda, R.; Pereira, S.L.; Phillips, B.E.; et al. Cocoa Flavanols Adjuvant to an Oral Nutritional Supplement Acutely Enhances Nutritive Flow in Skeletal Muscle without Altering Leg Glucose Uptake Kinetics in Older Adults. Nutrients 2021, 13, 1646. [CrossRef] [PubMed]

36. Phillips, B.E.; Atherton, P.J.; Varadhan, K.; Limb, M.C.; Williams, J.P.; Smith, K. Acute cocoa flavanol supplementation improves muscle macro- and microvascular but not anabolic responses to amino acids in older men. Appl. Physiol. Nutr. Metab. 2016, 41, 548-556. [CrossRef]

37. Ullmann, U.; Haller, J.; Decourt, J.D.; Girault, J.; Spitzer, V.; Weber, P. Plasma-kinetic characteristics of purified and isolated green tea catechin epigallocatechin gallate (EGCG) after 10 days repeated dosing in healthy volunteers. Int. J. Vitam. Nutr. Res. 2004, 74, 269-278. [CrossRef]

38. Hadi, S.; Alipour, M.; Aghamohammadi, V.; Shahemi, S.; Ghafouri-Taleghani, F.; Pourjavidi, N.; Foroughi, M.; Chraqipoor, M. Improvement in fasting blood sugar, anthropometric measurement and hs-CRP after consumption of epigallocatechin-3-gallate (EGCG) in patients with type 2 diabetes mellitus. Nutr. Food Sci. 2019, 50, 348-359. [CrossRef]

39. Wilkinson, D.J.; Bukhari, S.S.I.; Phillips, B.E.; Limb, M.C.; Cegielski, J.; Brook, M.S.; Rankin, D.; Mitchell, W.K.; Kobayashi, H.; Williams, J.P.; et al. Effects of leucine-enriched essential amino acid and whey protein bolus dosing upon skeletal muscle protein synthesis at rest and after exercise in older women. Clin. Nutr. 2018, 37, 2011-2021. [CrossRef]

40. Dinenno, F.A.; Jones, P.P.; Seals, D.R.; Tanaka, H. Limb blood flow and vascular conductance are reduced with age in healthy humans: Relation to elevations in sympathetic nerve activity and declines in oxygen demand. Circulation 1999, 100, 164-170. [CrossRef] [PubMed] 
41. Sjoberg, K.A.; Rattigan, S.; Hiscock, N.; Richter, E.A.; Kiens, B. A new method to study changes in microvascular blood volume in muscle and adipose tissue: Real-time imaging in humans and rat. Am. J. Physiol. Heart Circ. Physiol. 2011, 301, H450-H458. [CrossRef]

42. Corretti, M.C.; Anderson, T.J.; Benjamin, E.J.; Celermajer, D.; Charbonneau, F.; Creager, M.A.; Deanfield, J.; Drexler, H.; Gerhard-Herman, M.; Herrington, D.; et al. Guidelines for the ultrasound assessment of endothelial-dependent flow-mediated vasodilation of the brachial artery: A report of the International Brachial Artery Reactivity Task Force. J. Am. Coll. Cardiol. 2002, 39, 257-265. [CrossRef]

43. Purkayastha, S.; Sorond, F. Transcranial Doppler ultrasound: Technique and application. Semin. Neurol. 2012, 32, 411-420. [CrossRef] [PubMed]

44. Sorond, F.A.; Lipsitz, L.A.; Hollenberg, N.K.; Fisher, N.D. Cerebral blood flow response to flavanol-rich cocoa in healthy elderly humans. Neuropsychiatr. Dis. Treat. 2008, 4, 433-440. [PubMed]

45. Sorond, F.A.; Schnyer, D.M.; Serrador, J.M.; Milberg, W.P.; Lipsitz, L.A. Cerebral blood flow regulation during cognitive tasks: Effects of healthy aging. Cortex 2008, 44, 179-184. [CrossRef]

46. Englund, E.K.; Rodgers, Z.B.; Langham, M.C.; Mohler, E.R., 3rd; Floyd, T.F.; Wehrli, F.W. Simultaneous measurement of macroand microvascular blood flow and oxygen saturation for quantification of muscle oxygen consumption. Magn. Reson. Med. 2018, 79, 846-855. [CrossRef] [PubMed]

47. Abumrad, N.N.; Rabin, D.; Diamond, M.P.; Lacy, W.W. Use of a heated superficial hand vein as an alternative site for the measurement of amino acid concentrations and for the study of glucose and alanine kinetics in man. Metabolism 1981, 30, 936-940. [CrossRef]

48. Heiss, C.; Schroeter, H.; Balzer, J.; Kleinbongard, P.; Matern, S.; Sies, H.; Kelm, M. Endothelial function, nitric oxide, and cocoa flavanols. J. Cardiovasc. Pharm. 2006, 47 (Suppl. 2), S128-S135. [CrossRef] [PubMed]

49. Mitchell, W.K.; Phillips, B.E.; Wilkinson, D.J.; Williams, J.P.; Rankin, D.; Lund, J.N.; Smith, K.; Atherton, P.J. Supplementing essential amino acids with the nitric oxide precursor, l-arginine, enhances skeletal muscle perfusion without impacting anabolism in older men. Clin. Nutr. 2017, 36, 1573-1579. [CrossRef] [PubMed]

50. Atherton, P.J.; Etheridge, T.; Watt, P.W.; Wilkinson, D.; Selby, A.; Rankin, D.; Smith, K.; Rennie, M.J. Muscle full effect after oral protein: Time-dependent concordance and discordance between human muscle protein synthesis and mTORC1 signaling. Am. J. Clin. Nutr. 2010, 92, 1080-1088. [CrossRef]

51. Da Silva, W.; Machado, A.S.; Souza, M.A.; Mello-Carpes, P.B.; Carpes, F.P. Effect of green tea extract supplementation on exercise-induced delayed onset muscle soreness and muscular damage. Physiol. Behav. 2018, 194, 77-82. [CrossRef]

52. Murase, T.; Haramizu, S.; Shimotoyodome, A.; Tokimitsu, I.; Hase, T. Green tea extract improves running endurance in mice by stimulating lipid utilization during exercise. Am. J. Physiol. Regul. Integr. Comp. Physiol. 2006, 290, R1550-R1556. [CrossRef] [PubMed]

53. Chang, Y.C.; Liu, H.W.; Chan, Y.C.; Hu, S.H.; Liu, M.Y.; Chang, S.J. The green tea polyphenol epigallocatechin-3-gallate attenuates age-associated muscle loss via regulation of miR-486-5p and myostatin. Arch. Biochem. Biophys. 2020, 692, 108511. [CrossRef] [PubMed]

54. Onishi, S.; Ishino, M.; Kitazawa, H.; Yoto, A.; Shimba, Y.; Mochizuki, Y.; Unno, K.; Meguro, S.; Tokimitsu, I.; Miura, S. Green tea extracts ameliorate high-fat diet-induced muscle atrophy in senescence-accelerated mouse prone-8 mice. PLoS ONE 2018, 13, e0195753. [CrossRef]

55. Meador, B.M.; Mirza, K.A.; Tian, M.; Skelding, M.B.; Reaves, L.A.; Edens, N.K.; Tisdale, M.J.; Pereira, S.L. The Green Tea Polyphenol Epigallocatechin-3-Gallate (EGCg) Attenuates Skeletal Muscle Atrophy in a Rat Model of Sarcopenia. J. Frailty Aging 2015, 4, 209-215. [CrossRef] [PubMed]

56. Porter, M.M.; Stuart, S.; Boij, M.; Lexell, J. Capillary supply of the tibialis anterior muscle in young, healthy, and moderately active men and women. J. Appl. Physiol. 2002, 92, 1451-1457. [CrossRef] [PubMed]

57. Jakobsson, F.; Borg, K.; Edstrom, L. Fibre-type composition, structure and cytoskeletal protein location of fibres in anterior tibial muscle. Comparison between young adults and physically active aged humans. Acta Neuropathol. 1990, 80, 459-468. [CrossRef]

58. Rattigan, S.; Clark, M.G.; Barrett, E.J. Hemodynamic actions of insulin in rat skeletal muscle: Evidence for capillary recruitment. Diabetes 1997, 46, 1381-1388. [CrossRef]

59. Vincent, M.A.; Barrett, E.J.; Lindner, J.R.; Clark, M.G.; Rattigan, S. Inhibiting NOS blocks microvascular recruitment and blunts muscle glucose uptake in response to insulin. Am. J. Physiol. Endocrinol. Metab. 2003, 285, E123-E129. [CrossRef] [PubMed]

60. Ras, R.T.; Zock, P.L.; Draijer, R. Tea consumption enhances endothelial-dependent vasodilation; a meta-analysis. PLoS ONE 2011, 6, e16974. [CrossRef] [PubMed]

61. Jochmann, N.; Lorenz, M.; Krosigk, A.; Martus, P.; Bohm, V.; Baumann, G.; Stangl, K.; Stangl, V. The efficacy of black tea in ameliorating endothelial function is equivalent to that of green tea. Br. J. Nutr. 2008, 99, 863-868. [CrossRef] [PubMed]

62. Lorenz, M.; Rauhut, F.; Hofer, C.; Gwosc, S.; Muller, E.; Praeger, D.; Zimmermann, B.F.; Wernecke, K.D.; Baumann, G.; Stangl, K.; et al. Tea-induced improvement of endothelial function in humans: No role for epigallocatechin gallate (EGCG). Sci. Rep. 2017, 7, 2279. [CrossRef] [PubMed]

63. Alexopoulos, N.; Vlachopoulos, C.; Aznaouridis, K.; Baou, K.; Vasiliadou, C.; Pietri, P.; Xaplanteris, P.; Stefanadi, E.; Stefanadis, C. The acute effect of green tea consumption on endothelial function in healthy individuals. Eur. J. Cardiovasc. Prev. Rehabil. 2008, 15, 300-305. [CrossRef] [PubMed] 
64. Jowko, E. Green Tea Catechins and Sport Performance. In Antioxidants in Sport Nutrition; Lamprecht, M., Ed.; Taylor \& Francis Group, LLC: Boca Raton, FL, USA, 2015.

65. Birdsill, A.C.; Carlsson, C.M.; Willette, A.A.; Okonkwo, O.C.; Johnson, S.C.; Xu, G.; Oh, J.M.; Gallagher, C.L.; Koscik, R.L.; Jonaitis, E.M.; et al. Low cerebral blood flow is associated with lower memory function in metabolic syndrome. Obesity 2013, 21, 1313-1320. [CrossRef] [PubMed]

66. Vincent, M.A.; Clerk, L.H.; Lindner, J.R.; Klibanov, A.L.; Clark, M.G.; Rattigan, S.; Barrett, E.J. Microvascular recruitment is an early insulin effect that regulates skeletal muscle glucose uptake in vivo. Diabetes 2004, 53, 1418-1423. [CrossRef]

67. Wu, L.Y.; Juan, C.C.; Hwang, L.S.; Hsu, Y.P.; Ho, P.H.; Ho, L.T. Green tea supplementation ameliorates insulin resistance and increases glucose transporter IV content in a fructose-fed rat model. Eur. J. Nutr. 2004, 43, 116-124. [CrossRef] [PubMed]

68. Wu, L.Y.; Juan, C.C.; Ho, L.T.; Hsu, Y.P.; Hwang, L.S. Effect of green tea supplementation on insulin sensitivity in Sprague-Dawley rats. J. Agric. Food Chem. 2004, 52, 643-648. [CrossRef] [PubMed]

69. Jung, K.H.; Choi, H.S.; Kim, D.H.; Han, M.Y.; Chang, U.J.; Yim, S.V.; Song, B.C.; Kim, C.H.; Kang, S.A. Epigallocatechin gallate stimulates glucose uptake through the phosphatidylinositol 3-kinase-mediated pathway in L6 rat skeletal muscle cells. J. Med. Food 2008, 11, 429-434. [CrossRef]

70. Zhang, Z.F.; Li, Q.; Liang, J.; Dai, X.Q.; Ding, Y.; Wang, J.B.; Li, Y. Epigallocatechin-3-O-gallate (EGCG) protects the insulin sensitivity in rat L6 muscle cells exposed to dexamethasone condition. Phytomedicine 2010, 17, 14-18. [CrossRef]

71. Ueda, M.; Nishiumi, S.; Nagayasu, H.; Fukuda, I.; Yoshida, K.; Ashida, H. Epigallocatechin gallate promotes GLUT4 translocation in skeletal muscle. Biochem. Biophys. Res. Commun. 2008, 377, 286-290. [CrossRef] [PubMed]

72. Narumi, K.; Sonoda, J.; Shiotani, K.; Shigeru, M.; Shibata, M.; Kawachi, A.; Tomishige, E.; Sato, K.; Motoya, T. Simultaneous detection of green tea catechins and gallic acid in human serum after ingestion of green tea tablets using ion-pair high-performance liquid chromatography with electrochemical detection. J. Chromatogr. B Anal. Technol. Biomed Life Sci. 2014, 945-946, 147-153. [CrossRef] [PubMed]

73. Nakagawa, K.; Okuda, S.; Miyazawa, T. Dose-dependent incorporation of tea catechins, (-)-epigallocatechin-3-gallate and (-)-epigallocatechin, into human plasma. Biosci. Biotechnol. Biochem. 1997, 61, 1981-1985. [CrossRef] [PubMed]

74. Morin, L.; Johnell, K.; Laroche, M.L.; Fastbom, J.; Wastesson, J.W. The epidemiology of polypharmacy in older adults: Registerbased prospective cohort study. Clin. Epidemiol. 2018, 10, 289-298. [CrossRef] [PubMed] 